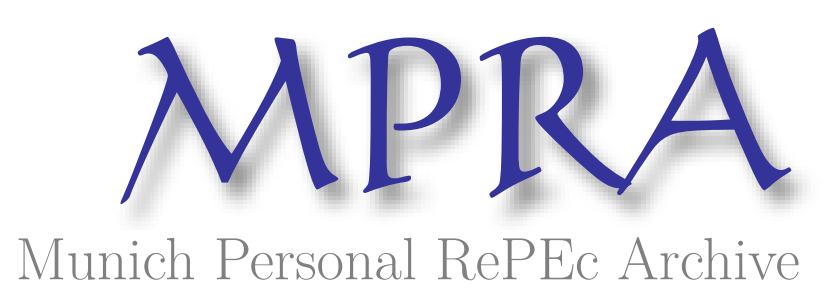

\title{
Price and Income Elasticity of Residential Electricity Consumption in Khorezm
}

Eshchanov, Bahtiyor and Grinwis, Mona and Salaev, Sanatbek

Vrije Universiteit Brussel, Vrije Universiteit Brussel, Urgench State University

2011

Online at https://mpra.ub.uni-muenchen.de/106240/ MPRA Paper No. 106240, posted 25 Feb 2021 07:57 UTC 


\title{
Chapter 10 \\ Price and Income Elasticity of Residential Electricity Consumption in Khorezm
}

\author{
Bahtiyor Eshchanov, Mona Grinwis, and Sanaatbek Salaev
}

\begin{abstract}
Price or income elasticity of demand is the percentage change in electricity demand resulting from a one-percent change in its price or income. Information on price and income elasticity of demand for electricity is crucial for formulating appropriate reform policies. In Central Asian economies with a less-developed industrial sector, the share of residential electricity consumption is relatively high. Residential electricity consumers are known to be more flexible with respect to price- and income-related changes and to adapt to these changes relatively fast. Knowledge about price and income elasticity of electricity demand is crucial for implementing, for instance, tariff reforms. The aim of this study is to estimate the short-term price and income elasticity of residential electricity demand using panel data based on time series of 6 years for the 12 districts of the Khorezm region, Uzbekistan, under the condition of data limitations. Using a unique dataset, the study attempts to identify the best proxy for the unobservable income variable. As for the price of electricity, nominal and real electricity prices tended to be growing between 2002-2007 from 7.0 Uzbek Soums (UZS) to 42.3 UZS (nominal), and 7.0 to 33.5 UZS (real), respectively, while the US\$ equivalent of the nominal price decreased from 6.23 US cents in 2002 to 3.35 US cents in 2007. Residential electricity demand is relatively price inelastic (between 0 and -1) in the short run. The study further tests the validity of indicators such as industrialization and growth in residential area as alternative measures of economic development that
\end{abstract}

\footnotetext{
B. Eshchanov $(\square) \bullet$ M. Grinwis

Faculty of Economic, Political and Social Sciences and Solvay Business School,

Vrije Universiteit Brussel, Pleinlaan 2, Brussels 1050, Belgium

e-mail: bahtiyor.eshchanov@vub.ac.be; mona.grinwis@vub.ac.be

\section{S. Salaev}

Urgench State University, Khamid Olimjan str., 14, Urgench 220100 Khorezm, Uzbekistan e-mail: s_sanat@list.ru
} 
cannot be captured by income. The results suggest that the income elasticities have a low value. The industrialization rate variable has a high value of demand determination. The growth in residential area used in this study as explanatory variable requires more precise data to be conclusive.

Keywords Electricity demand - Short-run elasticity - Panel data - Transition economies • Central Asia

\subsection{Introduction}

The availability of affordable, secure and environmentally friendly energy is a key to welfare, economic growth and sustainable development (Karimov 1998). Because of the scarcity of this kind of energy source, it is undoubtedly important to use the present sources effectively (Figueres and Philips 2007). This is particularly true in developing and transitional countries that usually have an enormous potential for increasing energy efficiency, which in turn could be exploited through adequate and appropriate reform policies.

Among the many differences between developed and developing countries, specific factors such as the use of traditional types of energy, ${ }^{1}$ process of transition to modern energies, and structural deficiencies in various sectors of the economy, inadequate investment decisions and misleading subsidies (Urban et al. 2007) are to be underlined in line with the commonly accepted inefficiency in electricity generation, distribution and consumption. Moreover, in developing countries, residential electricity demand is characterized by rapid growth over the last two decades of the last century (Filippini and Pachauri 2002), and the price and income elasticity of electricity consumption has been shown to be unstable over time (Holtedahl and Joutz 2004). This is illustrated in particular in countries of the former Soviet Union, which were previously part of a centralized system and subjected to objectives dictated by Moscow. Since their independence in 1991, these countries have had to reform their energy sector (IMF 2002). For example, the rich oil and gas reserves in Central Asian countries $(\mathrm{CAC})^{2}$ had been exploited during the Soviet era for serving overall objectives but had not aimed at supporting the economic development and growth of the individual countries.

In this regard, CAC transition economies can be grouped separately among the developing countries. They share unique similarities such as (i) slow growth in electricity consumption despite their recent rapid economic development and population growth, (ii) identical energy generation systems built during the Soviet era (e.g., in terms of technological performance and efficiency levels), (iii) introduction of energy sector reform and pricing policies with a high level of subsidization,

\footnotetext{
${ }^{1}$ Such as firewood, cotton stalks, reeds, etc.

${ }^{2}$ Kazakhstan, Kyrgyzstan, Tajikistan, Turkmenistan and Uzbekistan.
} 
(iv) pace of macro-economic stability (e.g., GDP growth rate, inflation), and (v) structure of national economies with a high share of the agriculture sector (Dowling and Wignaraja 2006) except for Kazakhstan. Although the newly independent CAC announced energy sector reform policies in the aftermath of independence in 1991, these have been introduced with different intensity and pace. Also, until today, energy saving opportunities have not been tackled, although they could be achieved through relatively simple policy measures. A correct pricing that leads to an efficient consumption of electricity is among these measures.

Given that residential electricity consumption constitutes on average more than one fourth $(27.5 \%)$ of the total global energy demand (EarthTrends 2005) with an even higher share in most non-industrialized developing countries, it is particularly important to consider this component in overall electricity consumption. In Uzbekistan, for instance, the share of total primary energy consumed by the residential sector was as high as 39\% in 2005 (EarthTrends 2005) and therefore much higher than the global average. Therefore, developing and applying price related measures for the residential electricity consumers increases efficiency and consequently enhances the welfare of the people (Dodonov et al. 2004). As increasing the efficiency of electricity consumption is considered to be part of the solutions to the scarcity of energy sources it is important to identify the determinants of residential electricity consumption such as price and income. Knowing price and income elasticities is crucial for the development of a new energy policy.

\subsection{Residential Electricity Demand Modeling}

Knowledge about residential electricity demand is vital for formulating energy pricing policies, given the significant share of residential electricity consumption in the overall electricity demand. However, electricity producers in CAC are known for oversupplying (Atakhanova and Howie 2007) or undersupplying (Komilov 2002) residential consumers. Consequently, the current residential consumption does not reflect the real demand. In a free market, such excess supply or demand would lead to price changes and in the end could clear such market disturbances.

Once the determinants of demand and magnitude of price and income elasticity of residential electricity consumption are known, the authorities can make better informed decisions to introduce necessary reforms in electricity generation, distribution and consumption efficiency. However, data on most variables are only available for short periods of a maximum of 10 years, while demand functions need longer time series of a period of 30 years and more (Dilaver and Hunt 2011), which are unavailable for most of the post Soviet countries. Consequently, to obtain plausible estimates for the short-run price and income elasticity of electricity consumption, the use of more sophisticated econometric methods presently seems a sensible approach to fill data gaps. Although residential energy demand modeling received a strong impetus after the early 1970s, mainly triggered by the global energy crisis, to date there is no all-encompassing modeling approach (Bhattacharyya 
and Timilsina 2010). Most of the models developed refer to pioneering work on residential electricity demand in the USA by Fisher and Kaysen (1962) and consider developed economies, whereas empirical approaches specifically designed for developing countries are still in their early stages of development and require a more spatially explicit approach of each specific geographic location.

Residential electricity demand models are classified into two groups: (i) models based on an end-users approach (input-output analysis) and (ii) macro-economic models based on an econometric approach (Bhattacharyya and Timilsina 2010). While end-user models are known for their higher data requirements and need of human resources to handle the overall process of modeling, they are recommended for developed countries due to their higher precision (World Bank 2004). The econometric approach is presently most widely applied due to its ability to cope with data limitations. Furthermore, due to their simplicity, macro-economic models are therefore presently preferred. Fisher and Kaysen (1962) used growth rate in electricity utilizing appliance stock as a proxy to income, together with price and income of households for 1946-1957 in the USA, and determined income and price elasticity of the short- and long-run demand for electricity. Halvorsen (1975) included natural gas price as a substitute good price in an electricity demand model to capture the interrelation between demand for electricity and demand for natural gas. Therefore, he introduced area and temperature-related data to capture the fundamental demand components. In contrast, Holtedahl and Joutz (2004) used urbanization as a proxy for a stock of electric appliances to identify economic development characteristics and changes in the stock of electric appliances, thus avoiding the shortcomings of applying Fisher's and Kaysen's approach to developing countries. Halicioglu (2007) confirmed the validity of the urbanization variable as a proxy for the stock of electric appliances in Turkey. In a study funded by the Bank World (2004), the aggregated electricity demand in CAC was estimated through the total sales in GWh for the electricity sector as a whole, not distinguishing the different consumer categories such as the industry, agriculture, services and residential consumers. Atakhanova and Howie (2007) used the industrialization rate of the provinces of Kazakhstan to capture economic development factors that are not captured by income. The industrialization rate was measured by the contribution of the regional industry sector in the gross regional product (GRP). Aside from the study by Atakhanova and Howie (2007), who modeled electricity demand for Kazakhstan and estimated the price and income elasticity of demand for electricity for the industrial, service and residential consumers, we know of no other study that has addressed the price and income elasticity of electricity in CAC.

The objective of the present study is to estimate the price and income elasticity in the Khorezm region in northwest Uzbekistan through econometric modeling under conditions of data limitations, especially with respect to the unobservable income variable. Apart from fundamental determinants of demand (price and income proxies), this study also uses proxies to capture economic development that possibly cannot be captured with income proxies. Data on price of electricity, income, industrialization rate and increase in residential areas were used as key 
determinants to estimate electricity consumption in this region. Thus, this study attempts to address the special characteristics of electricity demand such as the potential relation with the size of new dwellings.

\subsection{Methodology}

Elasticity of energy demand is a measure that denotes the responsiveness of the quantity demanded of energy (electricity in this case) to a change in its price or consumers' incomes. It gives the percentage change in quantity demanded in response to a $1 \%$ change in price or income while holding everything else constant. A large number of empirical studies have estimated the price and income elasticity of energy demand. The interest in price and income elasticity of demand is high because these factors are vital when forecasting energy demand (Medlock 2009). The price and income elasticity of demand are unit-free measures. In general the price elasticity of demand is negative meaning that an increase in the price of a good leads to a decrease in the quantity demand. With the income elasticity of demand this is different: an increase in income tends to increase the quantity demanded, depending on the kind of goods. So usually the income elasticity of demand will be positive.

\subsubsection{Description of the Study Region}

Twelve administrative districts (ten district and two city administrations) in the Khorezm region in northwest Uzbekistan form the basis of our study. This region is representative of both Uzbekistan and the neighboring countries. From the approximate 1,500,000 people (as of 2008), about $75 \%$ are rural and $25 \%$ are considered urban. The income of the rural population depends to a large extent on income from agricultural activities, notably from cotton production (Rudenko et al. 2008). Cotton is the dominant crop in the region. Khorezm shares with other regions in CAC a common culture and history that directly impacts energy consumption patterns. The region also has similar climatic conditions with short, cold winters and long, hot summers that directly influence household demand for energy for heating, lighting and cooking (Conrad 2006; Conrad et al. 2011). The average size of a household in Khorezm is 6-10 persons.

\subsubsection{Measuring Determinants of Electricity Demand}

In previous studies, the panel-data approach was successfully applied to estimate either the short-term elasticity of demand or to capture the cross-sectional variation of electricity consumption behavior within sub-regions (e.g. Garcia-Cerrutti 2000; 
Narayan et al. 2007; Cebula 2010; Eskeland and Mideksa 2010; Nakajima 2010). For key indicators such as income and urbanization rate, panel data of the 12 districts for 2002-2007 were used to cope with the incompleteness of the long-term dataset. This panel data consists of time series of 6 years for all 12 districts and thus of 72 observations for each variable.

The analysis used data from three sources. Residential electricity supply data were provided by the only regional electricity distribution company, ${ }^{3}$ and included information on a district level of annual residential electricity consumption (in $\mathrm{kWh}$ ) and annual average price (in local currency, Uzbek Soums, UZS ${ }^{4}$ ) of electricity. Since these data were collected for accounting purposes, they are very likely to be accurate. This dataset was matched with data from the regional statistical authority (UZISTIQBOLSTAT) on yearly observations of population monetary income, yearly increase in the housing space at district levels for 2002-2007, district level breakdown of the annual Gross Regional Product (GRP), cotton yields for the same period, and per capita monetary income per district. Next, per capita residential electricity consumption, per capita monetary income, per capita gross district income, and per capita increase in housing area were calculated. Since monetary income and price variables are nominal, the annual GDP deflator (World Bank 2010) was used to estimate real monetary income and price. Official average annual exchange rates of UZS-US\$ (Wikipedia 2011) were used as an alternative for the GDP deflator method. Hence, a balanced database was developed for 2002-2007.

To overcome the main empirical challenge in modeling residential electricity in CAC transition economies, the incomplete information on income was taken care of by estimating a standard energy demand function, with alternative imperfect proxies for income.

The following functional form of residential electricity demand was adopted from Halicioglu (2007) and Atakhanova and Howie (2007):

$$
\ln C_{t, i}=a_{0}+a_{1} \ln Y_{t, i}+a_{2} \ln P_{t, i}+a_{3} \ln I n d_{t, i}+a_{4} \ln N e w D w l_{t, i}+\varepsilon_{t, i}
$$

where:

$\mathrm{C}_{\mathrm{t}, \mathrm{i}}-$ residential electricity consumption per capita for the $\mathrm{t}^{\text {th }}$ year in the $\mathrm{i}^{\text {th }}$ district;

$\mathrm{Y}_{\mathrm{t}, \mathrm{i}}-$ income per capita for the $\mathrm{t}^{\text {th }}$ year in the $\mathrm{i}^{\text {th }}$ district;

$\mathrm{P}_{\mathrm{t}, \mathrm{i}}$ - real residential electricity price for the $\mathrm{t}^{\text {th }}$ year in the $\mathrm{i}^{\text {th }}$ district;

Ind $_{t, \mathrm{i}}-$ industrialization rate for the $\mathrm{t}^{\text {th }}$ year in the $\mathrm{i}^{\text {th }}$ district;

$\mathrm{NewDwl}_{\mathrm{t}, \mathrm{i}}$ increase in residential dwelling area per capita for the $\mathrm{t}^{\text {th }}$ year in the $\mathrm{i}^{\text {th }}$ district.

\footnotetext{
3"KhorezmElektrTarmoqlari" is Khorezm's regional department of the state-owned monopole electricity distribution network company.

${ }^{4}$ Uzbek Soum (UZS) exchange rate rose from 111.90 UZS in 2002 to 1263.80 UZS in 2007 for 1 US\$.
} 


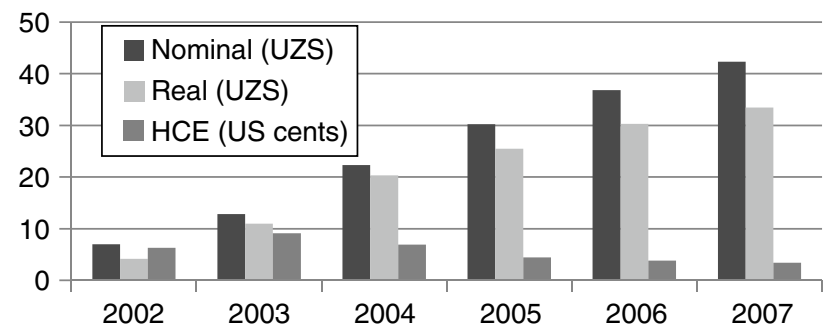

Fig. 10.1 Dynamics of the residential electricity price in Uzbekistan, 2002-2007 (in UZS and US cents $\mathrm{kWh}^{-1}$ ). HCE denotes hard currency equivalent of the nominal price (Source: Based on data from KhorezmElektrTarmoqlari and IMF)

The dependent variable is residential electricity consumption per capita (in kWh). Since alternative sources of energy, such as solar and wind energy, are not developed, it is assumed that electricity consumption per capita alone accurately represents the volume of electricity consumed by the residential consumers.

Two alternative proxies were used to measure the independent variable income. The real price (GDP deflator method) and the US\$ equivalent of real price were used for price estimations. Although the price of residential electricity increased steadily during 2002-2007, the hard currency equivalent (HCE) price in US cents decreased from 6.23 US cents $\mathrm{kWh}^{-1}$ in 2002 to 3.35 US cents $\mathrm{kWh}^{-1}$ in 2007 (Fig. 10.1)

The level of industrialization was estimated as the contribution of the district's industry sector to the GRP as previously suggested by Atakhanova and Howie (2007) for the regions of Kazakhstan. Given the low rate of industralisation in Khorezm (Rudenko et al. 2008), this seems an adequate proxy.

The model mainly served to test the fixed against random effects, since the impacts of district- or time-specific effects are unknown. The model with the best fit was selected.

In the following, the real monetary income of the population is estimated in 1,000 UZS per capita whilst the income proxy cotton yield is in tons per capita. The real price of electricity is in $\mathrm{UZS} \mathrm{kWh}^{-1}$, and the US\$ equivalent of the nominal price in US cent $\mathrm{kWh}^{-1}$ according to the corresponding year's average exchange rate. The share of each district's industry branch in the GRP is considered as industrialization rate and is given in 1,000 UZS per capita. "New dwellings" is a measure of per capita annual increase in residential area in square meters. This last variable is introduced as it is assumed that an increase in the quantity of housing will have an impact on electricity demand.

\subsection{Results and Discussion}

The estimations of the model are presented in Table 10.1. As the findings represent the short-run elasticity for 2002-2007, the magnitude of the estimated price elasticity was higher than that in previous studies in developing countries (e.g. Atakhanova and Howie 2007; Halicioglu 2007) and varied from -0.5161 to -0.8991 . When the 
Table 10.1 Regression findings of demand for electricity under alternative estimation techniques

\begin{tabular}{|c|c|c|c|c|c|c|c|c|}
\hline & \multicolumn{4}{|c|}{ Fixed effects model } & \multicolumn{4}{|c|}{ Random effects model } \\
\hline & \multicolumn{2}{|c|}{$\begin{array}{l}\text { Real monetary income of } \\
\text { the population }(1,000 \text { UZS } \\
\text { per capita) }\end{array}$} & \multicolumn{2}{|c|}{ Cotton yield (t per capita) } & \multicolumn{2}{|c|}{$\begin{array}{l}\text { Real monetary income of } \\
\text { the population }(1,000 \text { UZS } \\
\text { per capita) }\end{array}$} & \multicolumn{2}{|c|}{ Cotton yield ( $t$ per capita) } \\
\hline & Real price & $\mathrm{HCE}$ & Real price & $\mathrm{HCE}$ & Real price & $\mathrm{HCE}$ & Real price & HCE \\
\hline Constant & $\begin{array}{l}-0.6330 \\
(0.56)\end{array}$ & $\begin{array}{l}5.8246 \\
(0.01)^{*}\end{array}$ & $\begin{array}{l}-0.9421 \\
(0.40)\end{array}$ & $\begin{array}{l}3.4927 \\
(0.01)^{*}\end{array}$ & $\begin{array}{l}-1.2565 \\
(0.12)\end{array}$ & $\begin{array}{l}5.7875 \\
(0.00)^{*}\end{array}$ & $\begin{array}{l}-0.9558 \\
(0.25)\end{array}$ & $\begin{array}{l}5.2609 \\
(0.00)^{*}\end{array}$ \\
\hline Income & $\begin{array}{l}0.0456 \\
(0.70)\end{array}$ & $\begin{array}{l}-0.2682 \\
(0.15)\end{array}$ & $\begin{array}{l}-0.1708 \\
(0.25)\end{array}$ & $\begin{array}{l}-0.0990 \\
(0.52)\end{array}$ & $\begin{array}{l}-0.0437 \\
(0.01)^{*}\end{array}$ & $\begin{array}{l}-0.0938 \\
(0.00)^{*}\end{array}$ & $\begin{array}{l}0.0958 \\
(0.08)^{* * *}\end{array}$ & $\begin{array}{l}0.2058 \\
(0.00)^{*}\end{array}$ \\
\hline Price & $\begin{array}{l}-0.5436 \\
(0.00)^{*}\end{array}$ & $\begin{array}{l}-0.8991 \\
(0.00)^{*}\end{array}$ & $\begin{array}{l}-0.6087 \\
(0.00)^{*}\end{array}$ & $\begin{array}{l}-0.6446 \\
(0.00)^{*}\end{array}$ & $\begin{array}{l}-0.5473 \\
(0.00)^{*}\end{array}$ & $\begin{array}{l}-0.6898 \\
(0.00)^{*}\end{array}$ & $\begin{array}{l}-0.5381 \\
(0.00)^{*}\end{array}$ & $\begin{array}{l}-0.5161 \\
(0.00)^{*}\end{array}$ \\
\hline Industrialization & $\begin{array}{l}1.3745 \\
(0.00)^{*}\end{array}$ & $\begin{array}{l}0.0090 \\
(0.95)\end{array}$ & $\begin{array}{l}1.6465 \\
(0.00)^{*}\end{array}$ & $\begin{array}{l}0.2127 \\
(0.21)\end{array}$ & $\begin{array}{l}1.4435 \\
(0.00)^{*}\end{array}$ & $\begin{array}{l}0.0431 \\
(0.70)\end{array}$ & $\begin{array}{l}1.3201 \\
(0.00)^{*}\end{array}$ & $\begin{array}{l}-0.0590 \\
(0.64)\end{array}$ \\
\hline New Dwellings & $\begin{array}{l}-0.1726 \\
(0.56)\end{array}$ & $\begin{array}{l}0.3648 \\
(0.01)^{*}\end{array}$ & $\begin{array}{l}-0.1797 \\
(0.23)\end{array}$ & $\begin{array}{l}0.3555 \\
(0.02)^{*}\end{array}$ & $\begin{array}{l}-0.0597 \\
(0.43)\end{array}$ & $\begin{array}{l}0.1311 \\
(0.09)^{* *}\end{array}$ & $\begin{array}{l}-0.1098 \\
(0.25)\end{array}$ & $\begin{array}{l}0.0190 \\
(0.81)\end{array}$ \\
\hline $\mathrm{N}$ & 72 & 72 & 72 & 72 & 72 & 72 & 72 & 72 \\
\hline F-statistics & 27.51 & 25.14 & 28.40 & 24.00 & 141.34 & 120.49 & 131.50 & 93.70 \\
\hline R2 within & 0.6628 & 0.6423 & 0.6698 & 0.6315 & 0.6529 & 0.6209 & 0.6483 & 0.5824 \\
\hline $\mathrm{R} 2$ between & 0.0002 & 0.7582 & 0.0171 & 0.4109 & 0.8071 & 0.7574 & 0.7500 & 0.5960 \\
\hline $\mathrm{R} 2$ overall & 0.5350 & 0.4952 & 0.5382 & 0.2516 & 0.6784 & 0.6427 & 0.6625 & 0.5831 \\
\hline
\end{tabular}

Note: $\mathrm{p}$ values are in parenthesis; $*$ and $* *$ indicate $5 \%$ and $10 \%$ levels of significance respectively 
hard currency equivalent (HCE) of the nominal price was used, demand was more price elastic compared to when the real price ${ }^{5}$ was used, suggesting that even the real price may undervalue the true price of electricity. All coefficients of the real price and the HCE price were statistically significant at $p<0.001$. Although all models tested had statistically significant price coefficients and the expected signs, other estimates did not fit some criteria. All the models had at least one of the following flaws: (a) statistically insignificant coefficients, (b) unexpected signs, or (c) a coefficient with a magnitude that cannot be explained from an economic point of view.

Uzbekistan's population of 28,000,000 is the largest in Central Asia and about $45 \%$ of the entire population in the region. Currently, the price of electricity in Khorezm and in the whole of Uzbekistan does not include the true cost of the natural resources used to produce this electricity. About $80 \%$ of the total electricity in the country is produced using natural gas, which is expected to be depleted within the next $25-30$ years.

The contribution of renewable energy sources in generating electricity is very small (less than 1\%). To achieve long-term sustainability, the authorities in CAC must have a strong interest in achieving a correct pricing of electricity, unless they accept further subsidization of this sector. As long as energy is significantly undervalued, as is presently the case, price mechanisms to encourage energy savings will have only a limited impact, if at all. Furthermore, under priced electricity will disincentivize the introduction of renewable electricity sources, which currently would mean relatively high capital investment costs for the population in CAC. These countries currently have gross national per capita incomes that vary from 700 US\$ in Tajikistan to 870 US\$ in Kyrgyzstan, 1,100 US\$ in Uzbekistan, 3,420 US\$ in Turkmenistan, and 6,920 US\$ in Kazakhstan (World Bank 2009).

Furthermore, the present efficiency level of residential electricity consumption is rather low, which is due to outdated equipment (spiral-based light bulbs, valve-based TV sets, and old refrigerators). Consequently, it can be expected that an increase in income could slightly reduce the per capita electricity consumption. This is evidenced by the income coefficients of the random effects models with real monetary income as an income proxy, which were statistically significant with $p=0.010$ under real price and $p<0.001$ under HCE of the nominal price. As for the case of cotton yield as an income proxy, coefficients were statistically significant with a positive sign and relatively higher than in case of real monetary income. Therefore the signs in these statistically significant models were controversially under the two income proxies used (real monetary income and cotton yield). Only real monetary income supported the initial hypothesis of a negative relation between income and electricity consumption. Thus, due to the sign variation of the coefficients in the alternative models, the results for the income variable are inconclusive. Given the wide variety of non-monitored income-generating activities pursued by the rural population (Djanibekov 2008), and the unknown share of remittances from family members abroad to rural households (Conliffe 2009) for securing incomes and

${ }^{5}$ Real value is an adjusted price for the effect of inflation on the nominal price. 
livelihoods, the true income of the population is very likely underestimated when based solely on cotton yields. This explains in part the low fit of the income findings based on cotton yields. Despite this discrepancy, all other criteria are well supported by the random effects model with the real price. Moreoever, Hausman's specification test results imply that fixed effects estimates should be abandoned in favor of random effects estimates. This indicates that an increase in income may also lead to an increase in per capita residential electricity consumption. The positive effect of the income growth on decreasing per capita residential electricity consumption is also proven by the findings of the current short-run elasticity estimation.

The industrialization rate was positively elastic and statistically significant, but only under the conditions of a real price, and ranged from 1.3201 to 1.6465. This indicates that every 1,000 UZS per capita increase in industrial production will lead to more than $1 \mathrm{kWh}$ per capita increase in residential electricity consumption.

It was hypothesized that per capita increase in dwelling areas leads to an increase in per capita residential electricity consumption. For example, if a family in Khorezm with an average of six members formerly living together separates into two families living in two houses, the electricity consumption level (for one TV set, one refrigerator and ten light bulbs for six people) will rise with the split, as will the per capita dwelling area. In Uzbekistan, with its relatively high birth rate and rapidly increasing dwelling areas, this variable may be one of the important explanatory variables of residential electricity consumption. However, only three models out of the eight (moreover using HCE values of the price) supported the assumption of a high explanatory value of the dwelling area, as evidenced by the range of coefficients from 0.1311 to 0.3648 (Table 10.1). In the models with real price, the coefficients of the New Dwelling variable were statistically insignificant and had the opposite sign (an increase in dwelling area decreases the demand for electricity). Given the limitations of the present dataset and analyses, a more in-depth study of the current variable could clarify the present evidence that an increase in residential dwelling area leads to a significant increase in electricity consumption.

The overall goodness-of-fit of the models varied from 0.4952 to 0.6784 , with real monetary income and real price under random effects providing the best fit (Table 10.1). In general, the random effects variations were captured better than those of the fixed effects, implying that variation over time is captured more precisely compared to the variation in consumption behavior within districts. This suggests that (a) price and income elasticity of electricity demand over time is not stable, and (b) the distribution of income proxies within the districts is uneven.

Central Asian economies may be able to meet the domestic demand until about 2020 through the implementation of measures aiming at reducing electricity loss, rehabilitation of the existing generative capacity and regional trade. Given the expected rapid depletion of natural gas - at present the main source of energy in Uzbekistan - the implications of price-related measures (increase in price) could be fourfold:

1. The currently low efficiency level would be significantly improved, facilitating the process of the transition to electricity-efficient high-tech equipment; 
2. Further expansion of the fossil-based electricity generation sector would be dampened, leading to a more sustainable fossil-fuel use together with a lower increase in emissions;

3. The revenues to be expected from a higher price for electricity would generate more funds, which could be spent on diversifying the electricity supply sector, for instance by increasing the share of solar, wind and other renewable sources in places where these sources could generate a technically feasible capacity;

4. The increase in price, in line with facilitating an efficient consumption by the residential consumers, could prepare the ground for introducing renewable energy, making it more competitive with centrally supplied electricity.

A possible side effect of price-related changes may be an increased non-payment. A study by the Bank World (2004) estimated only $70-85 \%$ billing of the total electricity in CAC in 2002. Some non-residential consumers (i.e., mining industry) are not billed but use an exchange method of payment for the consumed electricity (Bank World 2004). Residential consumers are $100 \%$ billed. Avoiding this gap in revenue generation may require an increase in metering and accounting efforts.

\subsection{Conclusions}

An electricity price increase in Uzbekistan will definitely result in increased consumption efficiency and hence lead to a significant decline in per capita residential electricity consumption. But, even in that case, UzbekEnergo ${ }^{6}$ will need to increase the residential electricity supply due to the steady population growth. However, as the price of electricity for consumers other than residential ones increased simultaneously, it is necessary to determine the effect of price increase on the industrial, agricultural and other consumers to achieve a comprehensive energy reform policy. This requires, becoming acquainted with the characteristics of the energy consumption of these consumer groups.

The income elasticity of residential electricity consumption in the short run is assumed to be negatively elastic, which is due to the transition to high-tech electricity consumption by households. This hypothesis was not sufficiently well supported by the findings. On the contrary, empirical evidence demonstrates that income has a positive elasticity with small coefficients. As the standard of living of the population increases, its demand for electricity will also be growing. In addition, increases in incomes can change the price elasticity of the electricity demand by decreasing the effect of future price changes. Therefore, in line with price-related demand-regulation mechanism, UzbekEnergo needs to seek alternative control tools as well as measures for meeting the future residential energy demand. Introduction of renewable energy resources in the remote areas can be one of these measures. In some of the eight estimated models both industrialization and increase in dwelling space revealed

\footnotetext{
${ }^{6}$ State-owned monopole electricity supplier for all customers.
} 
(through their statistical significant coefficients) to be interesting new explanatory variables. Identifying such determinants of the electricity consumption is crucial for policy makers and demand forecasting, and could also be another important contribution for residential electricity demand modeling. Increased knowledge about the reform policy of UzbekEnergo, its current strategy, and short- and long-term planning would allow better appraising the present policy better and supporting the formulation of recommendations than presently possible.

\section{References}

Atakhanova Z, Howie P (2007) Electricity demand in Kazakhstan. Energy Policy 35:3729-3743

Bhattacharyya SC, Timilsina GR (2010) Modelling energy demand of developing countries: are the specific features adequately captured? Energy Policy 38:1979-1990

Cebula RJ (2010) Recent evidence on determinants of per residential customer electricity consumption in the U.S.: 2001-2005. J Econ Finance. doi:10.1007/s12197-12010-19159-12192

Conliffe A (2009) The combined impacts of political and environmental change on rural livelihoods in the Aral Sea region of Uzbekistan. PhD dissertation, Oxford University, Oxford

Conrad C (2006) Remote sensing based modeling and hydrological measurements to assess the agricultural water use in the Khorezm region, Uzbekistan. PhD dissertation, University of Würzburg, Würzburg

Conrad C, Schorcht G, Tischbein B, Sultonov M, Davletov S, Eshchanov R, Lamers JPA (2011) Agro-meteorological implications and trends of recent climate development in Khorezm. In: Martius C, Rudenko I, Lamers JPA, Vlek PLG (eds) Cotton, water, salts and Soums: economic and ecological restructuring in Khorezm, Uzbekistan. Springer, Berlin/Heidelberg/New York/ Dordrecht

Dilaver Z, Hunt L (2011) Industrial electricity demand for Turkey: a structural time series analysis. Energy Econ 33: p 426

Djanibekov N (2008) A micro-economic analysis of farm restructuring in Khorezm region, Uzbekistan. PhD dissertation, Bonn University, Bonn

Dodonov B, Opitz P, Pfaffenberger W (2004) How much do electricity tariff increases in Ukraine hurt the poor? Energy Policy 32:855-863

Dowling M, Wignaraja G (2006) Central Asia after fifteen years of transition: growth, regional cooperation, and policy changes. ADB working paper series on regional economic integration no. 3, Asian Development Bank, July 2006

EarthTrends (2005) Energy consumption by sector for Uzbekistan in 2005. Retrieved on 22 Jan 2011, from Earth trends environmental information of the World Resources Institute. http:// earthtrends.wri.org/pdf_library/data_tables/ene3_2005.pdf

Eskeland GS, Mideksa TK (2010) Electricity demand in a changing climate. Mitig Adapt Strateg Glob Chang 15(8):877-897

Figueres C, Philips M (2007) Scaling up demand-side energy efficiency improvements through programmatic CDM. ESMAP technical paper 120/107

Filippini M, Pachauri S (2002) Elasticity of electricity demand in urban Indian households. CEPE working paper, 16. Centre for Energy Policy and Economics Swiss Federal Institutes of Technology

Fisher FM, Kaysen C (1962) A study in econometircs: the demand for electricity in the United States. North-Holland Publishing House, Amsterdam

Garcia-Cerrutti LM (2000) Estimating elasticity of residential energy demand from panel county data using dynamic random variables models with heteroskedastic and correlated error terms. Resour Energy Econ 22:355-366 
Halicioglu F (2007) Residential electricity demand dynamics in Turkey. Energy Econ 29:199-210

Halvorsen R (1975) Residential demand for electric energy. Rev Econ Stat 57(1):12-18

Holtedahl P, Joutz FL (2004) Residential electricity demand in Taiwan. Energy Econ 26:201-224

IMF (2002) Energy sector quasi-fiscal activities in the countries of the former Soviet Union. International Monetary Fund working paper. Collective authors, March 2002

Karimov I (1998) Uzbekistan on the threshold of the twenty-first century: challenges to stability and progress. Palgrave Macmillan, New York p 163

Komilov A (2002) Renewable energy in Uzbekistan, potential and perspectives. Renewable Energy for Sustainable Development, DAAD and Carl Von Ossietzky Universitat Press, Oldenburg, pp 246-256

Medlock KB III (2009) Energy demand theory. In: Evans J, Hunt L (eds) International handbook on the economics of energy. Edward Elgar, Cheltenham/Northampton

Nakajima T (2010) The residential demand for electricity in Japan: an examination using empirical panel analysis techniques. J Asian Econ 21:412-420

Narayan PK, Smyth R, Prasad A (2007) Electricity consumption in G7 countries: a panel cointegration analysis of residential demand elasticity. Energy Policy 35:4485-4494

Rudenko I, Grote U, Lamers JPA (2008) Using a value chain approach for economic and environmental impact assessment of cotton production in Uzbekistan. In: Qi J, Evered KT (eds) Environmental problems of Central Asia and their economic, social, and security impacts, NATO science for peace and security series - C: environmental stability. Springer, Dordrecht, pp 361-380

Urban F, Benders RJ, Moll HC (2007) Modelling energy systems for developing countries. Energy Policy 35:3473-3482

Wikipedia (2011) Tables of historical exchange rates to the USD. Wikipedia - the free online encyclopedia, Retrieved on 02 Feb 2011 from The World Bank website: http://en.wikipedia. org/wiki/Tables_of_historical_exchange_rates_to_the_USD

World Bank (2004) Central Asia regional electricity export potential study. World Bank, Washington, DC

World Bank (2009) GNI (Atlas method). Country statistics, The World Bank database, Retrieved on 20 Mar 2011, from The World Bank website: www.data.worldbank.org

World Bank (2010) World development indicators. The World Bank, Retrieved on 02 Feb 2011, from The World Bank website: http://data.worldbank.org/data-catalog/world-developmentindicators?cid=GPD_WDI 